\title{
EXPLORING PARTICIPANT MOTIVATIONS TO TAKE PART IN AN ELITE, MULTINATIONAL, SPORT-FOR-DEVELOPMENT EVENT
}

\author{
JON WELTY PEACHEY,* GEORGE CUNNINGHAM,* ALEXIS LYRAS, $†$ \\ ADAM COHEN, $\ddagger$ AND JENNIFER BRUENING§ \\ *Department of Recreation, Sport and Tourism, University of Illinois at Urbana-Champaign, \\ Champaign, IL, USA \\ †Department of Government, Georgetown University, Washington, DC, USA \\ $\ddagger$ Department of Health Exercise and Sport Sciences, Texas Tech University, Lubbock, TX, USA \\ $\S$ Department of Educational Leadership, University of Connecticut, Storrs, CT, USA
}

\begin{abstract}
One neglected area of research in sport event management has been to examine the motivations of individuals to take part in large, multinational sport-for-development (SFD) events. The importance of examining such motivations is highlighted by SFD's frequent struggle with attracting individuals to the programs, despite well-meaning intentions and agendas. Hence, we undertook this study to examine participant motivations for attending the World Scholar-Athlete Games and World Youth Peace Summit, a combined, multinational SFD event with a peace agenda set in the US. We conducted two studies - one quantitatively focused and the other through personal interviews and focus groups. Results from both studies revealed that individuals were motivated to participate in order to engage in world learning, for skill development, and for the opportunity to travel, with world learning being the most prominent factor. International participants had higher mean scores on all factors than domestic participants, and sport participants were more motivated by skill development than fine arts participants. These findings imply that sport events with a peace focus should highlight socialization opportunities and the mission of the organization to attract participants, while still providing an environment of healthy competition and skill development.
\end{abstract}

Key words: Athlete motivation; Sport event participant motivation; Sport-for-development (SFD); Sport events; Multinational sport events; International sport events

\section{Introduction}

Much of the research on international sport events has centered upon large-scale, multinational events that target elite athletes, like the Olympic Games (Xu \& Pegg, 2007). Athletes are motivated to take part in these primarily for the opportunity to compete and test themselves against elite competition

Address correspondence to Jon Welty Peachey, Ph.D., Department of Recreation, Sport and Tourism, University of Illinois at UrbanaChampaign, MC-584, Champaign, IL 61820, USA. Tel: 217-244-2956; Fax: 217-244-1935; E-mail: jwpeach@illinois.edu 
(Vallerand, 1997, 2007). However, one neglected area of research in sport event management has been to examine the motivations of individuals to take part in large, multinational sport-for-development (SFD) events. We can define SFD as the use of sport to exert a positive influence on public health, the socialization of children, youth, and adults, the social inclusion of the disadvantaged, the economic development of regions and states, and on fostering intercultural exchange and conflict resolution (Lyras \& Welty Peachey, 2011; Sugden, 2008). Unlike many multinational sport events, where the purpose is primarily on sporting excellence, many SFD events have the primary goal of fostering peace, understanding, and cultural acceptance among people from disparate communities. Instead of focusing solely on athletic competition, these SFD events often combine sports with cultural and educational activities and programming to achieve their missions (Lyras \& Welty Peachey, 2011; Schulenkorf \& Edwards, 2012). As an illustrative example, the Gay Games (Federation of Gay Games, n.d.) is organized around high-level sport competition, but also includes cheer, choral activities, bands, and other cultural elements (Cunningham \& Melton, 2012).

A SFD event focused on both elite competition and a social cause or peace-centered mission would have a multilayered design scheme centered on both excellence and pleasure derived through its competitive sport offerings and related social, educational, and cultural activities. Typically, a sporting event is organized around one design scheme, such as pursuit of excellence (i.e., the event is organized such that participants come to compete against high-caliber opponents and the focus is on competition and winning) or pursuit of pleasure (i.e., the event is organized such that participants come to take part due to the pleasure derived from the activities alone) (Chelladurai, 1992). A layered design scheme, however, could lead to multiple motivations for individuals to participate, and these would potentially differ from motivations to take part in mainstream sport events or other social justice events. Thus, it is vital to understand participant motivations for these types of elite SFD events in order to contribute to a robust theoretical understanding of SFD participant motivations, as this line of theoretical inquiry is still in its infancy and requires further development and extensions (Lyras \& Welty Peachey, 2011).

In addition, the primacy of examining such motivations is highlighted by SFD's frequent struggle with attracting individuals to the programs, despite well-meaning intentions and agendas (Lyras \& Welty Peachey, 2011). Identifying motivational factors that can be attributable to participants in various SFD events with different missions and foci can thus be advantageous for organizers in recruiting and retaining participants, as events could be structured and designed to capitalize on these motivations. In addition, understanding initial motivations would be helpful in eventually converting participants to volunteers in order to sustain the events over the long term. Hence, we undertook this study to examine participants' motivations for attending. To do so, we conducted two studies-one quantitatively focused and the other through personal interviews and focus groups-at a large-scale, elite, multinational SFD event focused on developing peace and understanding among youth from various countries. In the following section, we present our conceptual framework.

\section{Conceptual Framework}

In drawing from Luthans (1998) and Ford (1992), we considered motivation to participate in SFD events as the processes, goals, and emotions that serve to energize people to participate and maintain their involvement in SFD events. Unfortunately, systematic investigation into what constitutes this motivation is lacking. This omission might be due to the complex nature of said events, as they commonly contain social, educational, and cultural elements (Lyras \& Welty Peachey, 2011; Schulenkorf \& Edwards, 2012), with various possible outcome foci. Given (a) the complex nature of SFD events and (b) the lack of a strong theoretical framework couched within the SFD literature to guide our investigation, we opted to draw from various literature bases, including leisure, physical activity, sport, and festivals, to identify possible motives for participation.

In reviewing this literature, we identified six possible motives that might energize people to 
participate and maintain their involvement in SFD events. The first motivation is socialization-a common element to which researchers have pointed in the youth sport context (Gill, Gross, \& Huddleston, 1983), among club sport participants (Recours, Souville, \& Griffet, 2004), among physical activity participants (Cunningham, 2007), in the leisure context (Manfredo, Driver, \& Tarrant, 1996), among elite athletes (Riemer \& Chelladurai, 1998), and in the art, music, or cultural festival context (Bowen \& Daniels, 2005; Crompton \& McKay, 1997; Nicholson \& Pearce, 2001). Within the context of SFD events, participants might be motivated by the desire to meet new people or develop friendships with others. Illustrative of this possibility, Riemer and Chelladurai (1998) observed that college athletes' commitment to their team was strongly associated with the quality of interactions they had with their teammates.

Other authors have theorized that participants engage in sport and physical activity endeavors as a way to further refine their skills and talents (Chelladurai, 1992; Cunningham, 2007; Gill et al., 1983; Treasure \& Roberts, 1994, 1998). For example, in an analysis of the Australian Scholar-Athlete Games, Dickson (2010) observed that the most significant motivator for participants was the pursuit of skill, or a desire to develop new talents and ideas. Gill et al. (1983), in recognizing the importance of this motivation for youth sport participants, argued that since "boys and girls want to learn and improve their skill, program organizers should not lose sight of this objective" (p. 9). Such sentiments are applicable within the context of the current study, as participants might pursue SFD opportunities as a way of further honing their skills, be they focusing on sport or fine arts.

Related to skill development is the participants' motivation to demonstrate excellence. A number of authors have suggested as much (Chelladurai, 1992; Cunningham, 2007; Recours et al., 2004; Treasure \& Roberts, 1994, 1998). For instance, participants might be energized to participate in SFD events when they have the ability to outclass other participants or demonstrate the superiority of their skills, whether sport or fine arts related. Events such as the Olympic Games, World Championships in various sports, and National Championships in intercollegiate sport in the US are organized around and capitalize on pursuit of excellence.

Other motivations might be more specific to SFD events. For instance, participants might also desire to take part in SFD events as a way of strengthening their capabilities as a world citizen. This motivation is consistent with the social justice orientation of many SFD events (Lyras \& Welty Peachey, 2011; Schulenkorf \& Edwards, 2012). For instance, the Homeless World Cup has many stated goals, including using sport to reengage persons who might otherwise be marginalized or mistreated in society (Sherry, 2010). Similarly, Schulenkorf and Edwards (2012) noted that the SFD event in their study focused on youth as a catalyst to promote social change among otherwise divided societies. Finally, Welty Peachey, Cohen, Borland, and Lyras (2013) observed that SFD volunteers realized increased awareness and appreciation of social justice, and following the event, they also expressed increased willingness to advocate on behalf of those issues. Recognizing these possibilities, participants might seek to become engaged in SFD opportunities as a way of becoming a better world citizen.

Another reason people might be energized to participate in SFD events is because of their desire to learn about different cultures. A number of researchers have noted these possibilities stemming from SFD events, including increases in youth participants' cultural capital (Spaajj, 2009) and cross-cultural friendships (Sugden, 2008). Similarly, researchers focusing on art, music, or cultural festivals have shown that people are motivated, in part, based on their desire for cultural exploration, such as discovering and experiencing customs and cultures otherwise unfamiliar to them (Bowen \& Daniels, 2005; Crompton \& McKay, 1997; Funk, Toohey \& Bruun, 2007). Collectively, these studies suggest the desire to learn about other cultures might represent another motivational dimension for SFD event participants.

Finally, some participants might engage in SFD events because of the opportunities to travel. This theme of travel and seeking new experiences was also common at the Australian University Games (Xu \& Pegg, 2007). Many SFD events are held in large, metropolitan areas, and when large enough, 
might afford international travel opportunities. Thus, for participants seeking travel opportunities, participation in SFD events might be ideal.

\section{Research Context for the Current Study}

To examine participant motivations to take part in an elite SFD event that had multiple layers of its design scheme, we selected the 2011 World Scholar-Athlete Games (WSAG) and World Youth Peace Summit (WYPS), a combined program held in Hartford, Connecticut. The mission of these events was to bring together the future leaders of the world to break down stereotypes, foster peace and understanding, and effect personal development and social change. The WSAG has been held every 4 years since 1993, and over 10,000 young people, ages $15-19$, have participated in the program. There were 525 youth (290 female and 235 male) from 40 countries who took part in both events in 2011.

The WSAG platform consisted of sport, fine arts, and educational programs. Young people participated as a specialist in one activity (either sports or fine arts). Approximately three fourths of the participants took part in the sport program and one fourth in the fine arts program. As mentioned previously, SFD events often combine sports with cultural and educational activities and programming to achieve their missions, instead of solely focusing on athletic competition (Lyras \& Welty Peachey, 2011; Schulenkorf \& Edwards, 2012). Doing so helps to more deeply enrich the various activities and, consequently, allows for more developmental opportunities. This was the case with the WSAG and WYPS, as both sport and fine arts participants were targeted in recruitment efforts. As such, we believed it was important to assess motivations of both the sport and fine arts participants in order to be aligned with the philosophical underpinnings of many SFD events, and the WSAG and WYPS specifically.

To take part in the WSAG and WYPS, young people had to be nominated by a teacher or coach and meet four selection criteria: (a) a distinguished record in her or his respective sport or fine arts activity (e.g., received all-conference or all-state designations if an athlete, or recognized in some distinguished capacity through honors or awards if a fine artist); (b) a notable academic record (e.g., achieved honor roll status or the equivalent); (c) a record of leadership in school, team, and community activities; and (d) previous participation in community service and volunteer work (WSAG, n.d.).

In contrast to most international sporting events, there were no national teams at the WSAG; participants from diverse countries and cultures were placed on the same teams or cultural activity groups. Organizers strategically placed young people from areas of the world that were in conflict on the same team or fine arts activity group, with the premise of using team-based goals, competition, and cooperation to facilitate understanding and acceptance (WSAG, n.d.). Sport participants engaged in practices and a competitive tournament, while the fine arts participants developed works that were showcased in recitals, displays, and at the closing ceremonies. As mentioned previously, all sport and fine arts participants took part in an educational component on each day of the WSAG. The young people heard a keynote address each morning on a salient topic, provided by a prominent world or national leader in government, business, education, or sport, and then broke into discussion groups to dialogue about questions and issues raised by the speakers. The purpose of the educational component was to foster dialogue and idea exchange and assist youth with developing action plans to take back to their home communities to serve as strategies for initiating social change (WSAG, n.d.).

The WYPS directly followed the WSAG, and had a specific goal of assisting the young people with further developing peace and community service projects that they could implement in their home communities. WYPS participants took part in workshops designed to help them develop action plans for change in their home communities, and to provide strategies for designing programs and projects at the local level using sport or the arts to positively impact communities. International leaders in program development, international policy, and leadership led the workshops. All of the WSAG participants took part in the WYPS; there were no additional individuals taking part in the WYPS who did not participate in the WSAG. Thus, 525 young people took part in the WYPS (the same as in the WSAG). These two events were combined, as a young person had to take part in both events in order to be accepted as a participant. 
Thus, the WSAG and WYPS were an elite, combined event that built upon excellence by providing high-caliber competition and activity groups through its sport and fine arts components. In addition, it presented the opportunity for skill development of participants. However, the WSAG and WYPS also had another layer of design that was presaged on the peace-centered mission-educational and social activities designed more around fostering world citizenship, socialization, and enhancing cultural understanding than pursuit of excellence or skill development. Hence, we deemed this context an appropriate setting to examine participant motivations to attend an elite, multinational event with multiple layers of foci (excellence, skill development, developing world citizens, enhancing cultural understanding, etc.), and to ascertain if these layers worked together to attract participants. To do so, we undertook a two-study investigation. Study 1 , a quantitative examination of the participant motivations, is presented first, followed by Study 2, which takes a qualitative approach to exploring motivations. We then offer a general discussion integrating the findings from both studies. In a call for mixed methods studies, Ercikan and Roth (2006) state the need for integrative approaches. Integrative approaches can provide appropriate forms of knowledge and utilize different units of analysis via diverse methodology. We believed it important to employ a mixed methods design in order to triangulate the findings and allow for deeper probing of motivations than could be obtained through quantitative methodology alone.

\section{Study 1}

In drawing from our conceptual framework, the purpose of Study 1 was to quantitatively examine young peoples' motives for participating in the WSAG and WYPS. The three research questions guiding Study 1 were as follows:

RQ1: What are the initial motivations of individuals for participating in the WSAG and WYPS?

RQ2: Which motivations for participating in the WSAG and WYPS are strongest?

RQ3: How do demographic characteristics influence motivations to participate in the WSAG and WYPS?

\section{Method}

Participants. Participants included 223 young people, ages 15-19, taking part in the WSAG and WYPS. The sample included 121 girls, 100 boys, and 2 people who did not indicate their gender. The mean age was 16.54 years $(S D=1.15)$. Most participants were from the US ( $n=136,61 \%)$, followed by Ireland ( $n=55,24.7 \%) ; 18$ countries were represented in all. Participants took part in a variety of events, including various kinds of sport (e.g., basketball, lacrosse, soccer; $n=164,73.5 \%$ ) and fine arts activities (e.g., art, creative writing, symphony; $n=51,22.9 \%)$.

Measures. Participants completed a questionnaire assessing their motivation to participate in the event and were asked to provide their demographic characteristics. The response rate was $42 \%$. Demographic items included questions related to their gender, age, country of origin, and sport played. Prior to distributing the questionnaire, we asked a panel of experts $(n=3)$ to review the items for content validity evidence. The panel provided recommendations for minor changes, but the general theme remained the same. The questionnaire was designed to capture the possible initial motivations related to a large-scale, elite international sporting event with the aim to foster peace, understanding, and cultural acceptance.

In drawing from the conceptual framework we developed for the study, we measured motivation with nine items. The stem read, "Please rate how the following factors influenced your decision to participate in the (event). Participating in the (Event) allows me to. ..." Items included "participate in elite competition," "better my athletic/fine arts skills," "participate on teams or groups with talented individuals," "travel the world," "visit the United States," "learn more about other cultures," "meet new people," "develop new friendships," and "become a better world citizen.” A Likert-type scale from 1 (strongly disagree) to 7 (strongly agree) anchored each item.

Procedures. Prior to initiating Study 1, institutional review board approval was received for both Study 1 and Study 2. As many of the participants were younger than age 18, we distributed parental 
permission forms prior to the event, and completed forms were returned via mail, electronically, or in person (at registration). For persons who had parental permission or who were 18 years or older, we distributed the questionnaire during their check-in and registration. All participants completed and returned the questionnaire and other forms pertinent to the event at that time.

\section{Results and Discussion}

Participation Motivation. Our first research question focused on motivations participants had to take part in the event. As such, we first conducted a principal components analysis with varimax rotation to explore the underlying factor structure of the participant motivations. Consistent with Hair, Black, Babin, Anderson, and Tatham (2006), we included factors with eigenvalues greater than 1.0, and we retained items with factor loadings greater than 0.50 . We also examined the total variance explained to assess model adequacy, with models explaining greater than $60 \%$ of the variance deemed satisfactory (Hair et al., 2006).

Results are presented in Table 1 . We report the factor loadings for each item, as well as each factor's eigenvalue, variance explained, internal consistency, mean, and standard deviation. The first factor contained items related to the participants' motivation to learn more about other cultures, meet new people, develop friendships, and become better world citizens. We termed this factor World Learning. The factor includes elements from several motivational dimensions in our conceptual framework, including socialization (see also Bowen \& Daniels, 2005; Crompton \& McKay, 1997; Cunningham, 2007; Gill et al., 1983; Manfredo et al., 1996; Recours et al., 2004), learning about different cultures (Crompton \& McKay, 1997; Spaajj, 2009; Sugden, 2008), and the social justice-oriented motivation of becoming a better world citizen (Lyras \& Welty Peachey, 2011; Schulenkorf \& Edwards, 2012; Welty Peachey et al., 2013).

The second factor, which we termed Skill Development, focused on the young persons' desires to participate in elite competition, better their skills, and participate with other talented individuals. This factor captures many of the motivations found in the sport-focused literature, including those set in the youth sport context (Gill et al., 1983), physical activity setting (Cunningham, 2007; Treasure \& Roberts, 1994, 1998), and elite sport environment (Riemer \& Chelladurai, 1998).

The final factor focused on traveling in the US and around the world, and we termed this Travel. Researchers focusing on festival attendees have also noted the primacy of having new experiences (Bowen \& Daniels, 2005; Crompton \& McKay, 1997)_something for which international travel is likely to allow. This theme of travel and seeking

Table 1

Results of Principal Components Analysis

\begin{tabular}{|c|c|c|c|}
\hline Item & Factor 1 & Factor 2 & Factor 3 \\
\hline Q7. Meet new people & 0.91 & & \\
\hline Q8. Develop new friendships & 0.90 & & \\
\hline Q9. Become a better world citizen & 0.82 & & \\
\hline Q6. Learn more about other cultures & 0.80 & & \\
\hline Q2. Better my athletic/fine arts skills & & 0.87 & \\
\hline Q3. Participate on teams or groups with talented individuals & & 0.84 & \\
\hline Q1. Participate in an elite competition & & 0.74 & \\
\hline Q5. Visit the United States & & & 0.92 \\
\hline Q4. Travel the world & & & 0.90 \\
\hline Eigenvalue & 3.04 & 2.15 & 1.74 \\
\hline Variance explained & 33.81 & 23.83 & 19.37 \\
\hline Cronbach’s alpha & 0.89 & 0.77 & 0.83 \\
\hline Mean & 6.17 & 5.59 & 3.82 \\
\hline SD & 0.97 & 1.11 & 2.28 \\
\hline
\end{tabular}

Note: Factor loadings for each item are presented. 
new experiences was also common at the Australian University Games (Xu \& Pegg, 2007).

Motivation Strength. Our second research question focused on differences in the motivations to determine which was strongest. To examine this issue, we computed paired sample t tests to examine mean differences in the motivation scores. We used Bonferroni correction to account for familywise error, thereby putting the critical value at $0.017(0.05,3)$. Results indicate the mean score for World Learning $(\mathrm{M}=6.17$, $\mathrm{SD}=0.97)$ was significantly higher than the corresponding scores for Skill Development $(\mathrm{M}=5.59, \mathrm{SD}=1.11)$ and Travel $(\mathrm{M}=3.82, \mathrm{SD}=2.28) \quad[\mathrm{t}(218)=7.27, \mathrm{p}<0.001$, and $\mathrm{t}(217)=15.05, \mathrm{p}<0.001$, respectively]. Additional analyses indicated the mean score for Skill Development was significantly higher than the score for Travel [ $\mathrm{t}(217)=11.92, \mathrm{p}<0.001]$.

Motivation Differences. Our final research question focused on potential motivational differences based on participant demographic characteristics. We computed a 2 (gender: female, male) $\times 2$ (country: US, International) $\times 2$ (activity: sport, fine arts) multivariate analysis of variance, with the three motivational factors serving as the dependent variables. Means and standard deviations are presented in Table 2. Results indicate significant multivariate effects for country [Wilks' lambda $=0.71$, $F(3,202)=27.21, p<0.001]$ and activity [Wilks' lambda $=0.91, F(3,202)$, = 6.97, $p<0.001]$. However, we did not observe significant effects for gender or any of the interaction terms.

Follow-up univariate analyses for country indicate significant differences for all motivational factors. As seen in Table 2, international participants had significantly higher mean scores than their US counterparts for World Learning $[F(1,204)=6.22, p<0.05$, $d=0.24]$, Skill Development $[F(1,204)=3.76$, $p=0.05, d=0.31]$, and Travel $[F(1,204)=80.66$, $p<0.001, d=1.63]$. The effect sizes for World Learning and Skill Development were moderate, while the effect for Travel was large.

Subsequent univariate analyses for activity revealed a significant effect only for Skill Development $[F(1,204)=12.58, p<0.001, d=0.53]$, and the magnitude of the effect was large. Results indicate sport participants were more motivated to improve their skills than were persons who took part in fine arts activities.

\section{Study 2}

The purpose of Study 1 was to quantitatively examine young peoples' motivations for participating in the WSAG and WYPS, consider differences in the strength of those motivations, and examine differences based on personal characteristics. In Study 2, we took a different approach to the study of motivation, and instead conducted in-depth qualitative analyses. Doing so allowed us to triangulate the data obtained in Study 2 with the Study 1 data to improve the robustness of the findings. Indeed, such an approach allows for greater probing and different analytical approaches for addressing a common issue (motivation). Given the nature of Study 2, we examined the first two research questions developed for Study 1:

RQ1: What are the initial motivations of individuals for participating in the WSAG and WYPS?

RQ2: Which motivations for participating in the WSAG and WYPS are strongest?

\section{Method}

We conducted focus groups and personal interviews with 34 current and former participants. In order to triangulate the data with Study 1, we attempted to conduct focus groups and personal interviews with individuals who did not complete the Study 1 survey. Two individuals who participated in Study 1 did also take part in Study 2, however. In total, 17 men and 17 women, 15-35 years old, were sampled. The four focus groups consisted of six to eight participants each, a number suggested by Krueger and Casey (2009), and seven additional personal interviews were conducted. The authors conducted all focus groups and personal interviews. We selected event participants (and former participants) from countries and activities that represented the diversity of the event. Alumni who were now volunteers were also targeted in an effort to gather motivation data from earlier events and preliminary data on transitioning to volunteering. 
Table 2

Means and Standard Deviations Based on Gender, Activity, and Nationality

\begin{tabular}{|c|c|c|c|c|c|}
\hline Gender & Activity & Nationality & Mean & SD & $N$ \\
\hline & & & \multicolumn{3}{|c|}{ DV: World Learning } \\
\hline \multirow[t]{9}{*}{ Female } & Fine Arts & International & 6.73 & 0.39 & 13 \\
\hline & & US & 6.18 & 0.97 & 24 \\
\hline & & Total & 6.37 & 0.85 & 37 \\
\hline & Sport & International & 6.34 & 0.75 & 27 \\
\hline & & US & 6.35 & 0.79 & 54 \\
\hline & & Total & 6.35 & 0.78 & 81 \\
\hline & Total & International & 6.47 & 0.68 & 40 \\
\hline & & US & 6.30 & 0.85 & 78 \\
\hline & & Total & 6.36 & 0.80 & 118 \\
\hline \multirow[t]{9}{*}{ Male } & Fine Arts & International & 6.80 & 0.27 & 5 \\
\hline & & US & 5.92 & 1.00 & 9 \\
\hline & & Total & 6.23 & 0.91 & 14 \\
\hline & Sport & International & 6.13 & 1.18 & 35 \\
\hline & & US & 5.87 & 1.03 & 45 \\
\hline & & Total & 5.98 & 1.10 & 80 \\
\hline & Total & International & 6.21 & 1.13 & 40 \\
\hline & & US & 5.88 & 1.10 & 54 \\
\hline & & Total & 6.02 & 1.07 & 94 \\
\hline \multirow[t]{10}{*}{ Total } & Fine Arts & International & 6.75 & 0.35 & 18 \\
\hline & & US & 6.11 & 0.97 & 33 \\
\hline & & Total & 6.33 & 0.86 & 51 \\
\hline & Sport & International & 6.22 & 1.01 & 62 \\
\hline & & & 6.13 & 0.94 & 99 \\
\hline & & Total & 6.17 & 0.97 & 161 \\
\hline & Total & International & 6.34 & 0.93 & 80 \\
\hline & & US & 6.12 & 0.94 & 132 \\
\hline & & Total & 6.21 & 0.94 & 212 \\
\hline & & & \multicolumn{3}{|c|}{ DV: Skill Development } \\
\hline \multirow[t]{9}{*}{ Female } & Fine Arts & International & 5.54 & 1.26 & 13 \\
\hline & & US & 5.24 & 0.96 & 24 \\
\hline & & Total & 5.34 & 1.07 & 37 \\
\hline & Sport & International & 5.88 & 1.17 & 27 \\
\hline & & US & 5.59 & 1.00 & 54 \\
\hline & & Total & 5.59 & 1.06 & 81 \\
\hline & Total & International & 5.77 & 1.20 & 40 \\
\hline & & US & 5.48 & 1.00 & 78 \\
\hline & & Total & 5.58 & 1.07 & 118 \\
\hline \multirow[t]{9}{*}{ Male } & Fine Arts & International & 5.07 & 1.57 & 5 \\
\hline & & & 4.44 & 0.85 & 9 \\
\hline & & Total & 4.67 & 1.14 & 14 \\
\hline & Sport & International & 5.96 & 1.04 & 35 \\
\hline & & US & 5.65 & 1.11 & 45 \\
\hline & & Total & 5.79 & 1.08 & 80 \\
\hline & Total & International & 5.85 & 1.13 & 40 \\
\hline & & US & 5.45 & 1.15 & 54 \\
\hline & & Total & 5.62 & 1.15 & 94 \\
\hline \multirow[t]{3}{*}{ Total } & Fine Arts & International & 5.41 & 1.32 & 18 \\
\hline & & US & 5.02 & 1.00 & 33 \\
\hline & & Total & 5.16 & 1.12 & 51 \\
\hline
\end{tabular}


Table 2

Means and Standard Deviations Based on Gender, Activity, and Nationality (Continued)

\begin{tabular}{|c|c|c|c|c|c|}
\hline Gender & Activity & Nationality & Mean & SD & $N$ \\
\hline & & & \multicolumn{3}{|c|}{ DV: Skill Development } \\
\hline & \multirow[t]{3}{*}{ Sport } & International & 5.92 & 1.09 & 62 \\
\hline & & US & 5.62 & 1.05 & 99 \\
\hline & & Total & 5.74 & 1.07 & 161 \\
\hline & \multirow[t]{3}{*}{ Total } & International & 5.81 & 1.16 & 80 \\
\hline & & US & 5.47 & 1.06 & 132 \\
\hline & & Total & 5.60 & 1.11 & 212 \\
\hline & & & \multicolumn{3}{|c|}{ DV: Travel } \\
\hline \multirow[t]{9}{*}{ Female } & Fine Arts & International & 6.04 & 1.52 & 13 \\
\hline & & US & 2.06 & 1.47 & 24 \\
\hline & & Total & 3.46 & 2.42 & 37 \\
\hline & Sport & International & 5.39 & 2.16 & 27 \\
\hline & & US & 2.85 & 2.02 & 54 \\
\hline & & Total & 3.70 & 2.38 & 81 \\
\hline & Total & International & 5.60 & 1.98 & 40 \\
\hline & & US & 2.61 & 1.87 & 78 \\
\hline & & Total & 3.62 & 2.39 & 118 \\
\hline \multirow[t]{9}{*}{ Male } & Fine Arts & International & 5.10 & 1.52 & 5 \\
\hline & & US & 2.33 & 1.64 & 9 \\
\hline & & Total & 3.32 & 2.06 & 14 \\
\hline & Sport & International & 5.71 & 1.75 & 35 \\
\hline & & US & 2.99 & 1.71 & 45 \\
\hline & & Total & 4.18 & 2.19 & 80 \\
\hline & Total & International & 5.64 & 1.72 & 40 \\
\hline & & US & 2.88 & 1.70 & 54 \\
\hline & & Total & 4.05 & 2.19 & 94 \\
\hline \multirow[t]{9}{*}{ Total } & Fine Arts & International & 5.78 & 1.54 & 18 \\
\hline & & US & 2.14 & 1.50 & 33 \\
\hline & & Total & 3.42 & 2.31 & 51 \\
\hline & Sport & International & 5.57 & 1.93 & 62 \\
\hline & & US & 2.91 & 1.88 & 99 \\
\hline & & Total & 3.94 & 2.30 & 161 \\
\hline & Total & International & 5.62 & 1.84 & 80 \\
\hline & & US & 2.72 & 1.82 & 132 \\
\hline & & Total & 3.81 & 2.30 & 212 \\
\hline
\end{tabular}

Individuals in the sample represented 19 different nationalities, eight different sports, and five fine arts activities (see Table 3).

The personal interview and focus group interview guides were semistructured to allow the interviewers to ask a standard set of questions but also explore tangents and probe for deeper understanding. To protect confidentiality, all study participants were given a pseudonym. Interviews and focus groups were conducted until data saturation was achieved. The data analysis process utilized open, axial, and selective coding (Strauss \& Corbin,
1990). The initial open coding procedure consisted of the first and second authors going line by line through the transcripts to identify salient motivational factors towards participating in the WSAG and WYPS. The next step entailed reducing these codes into common themes (axial coding). The authors met twice to review their codes, themes, and significant findings to strengthen the dependability of the findings. Finally, selective coding was utilized to choose relevant quotations from the study participants that successfully illustrated the themes that were identified during axial coding (Strauss \& 
Table 3

WSAG and WYPS Focus Group and Interview Participants

\begin{tabular}{|c|c|c|c|c|c|}
\hline Name & Age & Gender & Race & $\begin{array}{l}\text { Country of Origin/ } \\
\text { Nationality }\end{array}$ & Activity \\
\hline Ade & 17 & $\mathrm{M}$ & Black & US & Track and Field \\
\hline Alex & 31 & M & Asian & US & Volleyball \\
\hline Alfonso & 17 & M & Hispanic & $\begin{array}{l}\text { US (Guatemalan } \\
\text { nationality) }\end{array}$ & Track/Art \\
\hline Cabe & 17 & M & White & Ireland & Soccer \\
\hline Caryn & 17 & $\mathrm{~F}$ & White & Luxembourg & Tennis \\
\hline Casey & 15 & $\mathrm{~F}$ & White & US & Visual Arts \\
\hline Enam & 17 & $\mathrm{M}$ & Black & US (Ghana nationality) & Basketball \\
\hline Gillian & 31 & $\mathrm{~F}$ & Hispanic & Mexico & Dance \\
\hline Hasani & 15 & M & Black & US (Ghana nationality) & Basketball \\
\hline Ian & 16 & $\mathrm{M}$ & White & US & Soccer \\
\hline Jackie & 17 & $\mathrm{~F}$ & Hispanic/Asian & $\begin{array}{l}\text { US (Dominican/Chinese } \\
\text { nationality) }\end{array}$ & Visual Arts \\
\hline Jackson & 18 & M & Black & US & Basketball \\
\hline Jade & 18 & $\mathrm{~F}$ & Asian & Thailand & Choir \\
\hline Jake & 17 & M & Puerto Rican & Puerto Rico & Track and Field \\
\hline Klaudio & 20 & $\mathrm{~F}$ & Hispanic & Chile & Tennis \\
\hline Laura & 15 & $\mathrm{~F}$ & Caucasian & Australia & Basketball \\
\hline Leiko & 16 & $\mathrm{M}$ & Sinhalese & Sri Lanka & Basketball \\
\hline Leon & 24 & M & Hispanic & Uruguay & Theater \\
\hline Makela & 15 & $\mathrm{~F}$ & Black & US & Softball \\
\hline Manella & 16 & $\mathrm{~F}$ & Hispanic & Dominican Republic & $\begin{array}{l}\text { Creative } \\
\text { Writing }\end{array}$ \\
\hline Marge & 16 & $\mathrm{~F}$ & White & US & Fencing \\
\hline Martin & 27 & M & White & US & Swimming \\
\hline Melissa & 17 & $\mathrm{~F}$ & White & New Zealand & Theatre \\
\hline Miko & 18 & $\mathrm{~F}$ & Asian & US (Myanmar nationality) & Choir \\
\hline Nuncio & 18 & $\mathrm{M}$ & Hispanic & Nicaragua & Lacrosse \\
\hline Pax & 18 & $\mathrm{M}$ & Black & US (Nigerian nationality) & Basketball \\
\hline Peg & 35 & $\mathrm{~F}$ & Asian & Philippines & Basketball \\
\hline Peter & 18 & M & White & US & Basketball \\
\hline Ramon & 18 & $\mathrm{~F}$ & Black & US & Softball \\
\hline Rebecca & 18 & $\mathrm{~F}$ & White & Ireland & Theatre \\
\hline Ricky & 16 & M & White & US & Basketball \\
\hline Safina & 32 & $\mathrm{~F}$ & Black & Guyana & Choir \\
\hline Tanesha & 16 & $\mathrm{~F}$ & Black & US & Softball \\
\hline Tyler & 15 & $\mathrm{M}$ & Black/Hispanic & US & Basketball \\
\hline
\end{tabular}

Corbin, 1990). Member checks with participants were conducted to augment credibility of the results (Creswell, 1998). Study participants were given the opportunity to review their transcripts and study interpretations: none of the participants responded with concerns or issues.

\section{Results and Discussion}

Three main themes emerged that encompassed motivations of individuals to participate in the WSAG and WYPS: interpersonal connections (World Learning), skill development, and opportunity to travel and gain new experiences. These themes support the three factors developed within Study 1, as well as the relative strength of those factors, and are presented below utilizing quotations drawn from the focus groups and interviews.

Interpersonal Connections (World Learning). The most prevalent theme influencing initial participant motivation to attend the WSAG and WYPS was the desire to build social networks and interpersonal connections (World Learning). As with Study 1, these findings support previous research conducted with sport and music events that identified socialization (Bowen \& Daniels, 2005; Crompton 
\& McKay, 1997; Cunningham, 2007; Gill et al., 1983; Manfredo et al., 1996; Nicholson \& Pearce, 2001; Recours et al., 2004), learning about different cultures (Crompton \& McKay, 1997; Spaajj, 2009; Sugden, 2008), and, in the SFD context, the social justice-oriented motivation of becoming a better world citizen (Lyras \& Welty Peachey, 2011; Schulenkorf \& Edwards, 2012; Welty Peachey et al., 2013) as prominent motivations.

Some participants wanted to make new friends or meet people from diverse cultures. Others wished to be part of an initiative that would assist them in becoming a better world citizen and allow them the opportunity to give back to society. Still others simply enjoyed the opportunity to encounter new people in a fresh atmosphere, which yielded positive feelings, while some were motivated by the opportunity to gain new friends and social media (i.e., Facebook and Twitter) connections.

Leon was one participant who heard about the event and was motivated to apply because of the environment it could create:

When I listened about the World Scholar-Athlete Games, I thought that it would be a great opportunity to meet people from around the world.

Marge was another individual who appreciated the chance to broaden her horizons and enjoyed learning from a unique atmosphere, saying

I think for me at least, it's meeting people, and learning is equal. Partially because I'm really interested in all different cultures, and that was extremely appealing to me.

Gillian had been familiar with different cultures and was motivated to continue immersing herself in that atmosphere:

I studied in an international school all my life so I was familiarized with the idea of having people from everywhere in the playground. So it wasn't something that freaked me out, it was something that really encouraged me to come. . . . I just wanted to meet other people from other places.

Others like Jackie viewed the WSAG and the WYPS as a way to take a break from the environment that surrounded her at home, as she shared that
I had actually wanted to meet a lot more people from different states, different countries because in [my home town], everyone just knows each other sadly.

Martin, a former participant who returned to the event as a volunteer, reflected on his desires to attend in the past:

[WSAG] was my chance to be on my own and meet people. It wasn't about the athletic show; it was just about meeting people.

Casey was also one international participant who took part in the 2008 U.S. Scholar-Athlete Games, but who then came to the WSAG and WYPS because of her desires to meet people at the event:

One of [my goals] was to meet new people and make new friends. Because like last time, I made really good friends. And we all decided to come back together.

Beyond wanting to broaden their social circles through new acquaintances and friends, some of the participants desired to use the event as a means of fulfilling altruistic motivations to "give back" to their community. Alfonso, for example, was excited to attend the event for philanthropic reasons:

I came here to maybe learn more about what I can do to make a big difference. So I want to make a big difference, make the world a better place for kids.

Marge also wanted to use the WSAG and WYPS platform to build on her previous volunteer experience:

I've been involved in some social action things in my community and I mean it's a really great educational opportunity for me to develop the ways in which I can kind of make a difference.

Therefore, the WSAG and WYPS served to create interpersonal connections and foster World Learning. Some participants simply wanted to make new friends and expand their social circles, a similar finding to other large-scale event motivation studies (Crompton \& McKay, 2007; Xu \& Pegg, 2007) and festival motivation research (Bowen \& Daniels, 2005; Crompton \& McKay, 1997; Nicholson \& 
Pearce, 2001). Others wished to immerse themselves in various cultures and learn from their cohort (Crompton \& McKay, 1997; Dickson, 2010; Spaajj, 2009; Sugden, 2008). Unlike previous large-scale motivation studies, however, WSAG and WYPS participants had a desire to take this experience and utilize the skills and connections created for altruistic endeavors and give back to the community, an aspect of world citizenship important to SFD events (Lyras \& Welty Peachey, 2011; Schulenkorf \& Edwards, 2012; Welty Peachey et al., 2013). The additional components of the peace summit and workshops that were part of the WSAG and WYPS added a development and social justice focus that motivated participants, components that other sporting events usually do not possess.

Skill Development. The second most influential motivation was the desire to better one's skills and talents in an elite atmosphere. As we suggested in Study 1, this factor captures many of the motivations found in the sport-focused literature, including that set in the youth sport context (Gill et al., 1983), physical activity setting (Cunningham, 2007; Treasure \& Roberts, 1994, 1998), and elite sport environment (Riemer \& Chelladurai, 1998). In addition, skill development was a motivator for participants in the Australian Scholar-Athlete Games (Dickson, 2010) and the Masters' Games (Ryan \& Lockyer, 2002). Some participants in the current study were driven extrinsically by the opportunity to compete against the best, while others wanted to take advantage of the opportunity to improve their skills and ability.

Pax was one participant passionate about taking part in the event and representing the US in basketball:

I thought I was in the Olympics, I thought I was representing team USA out of all the smart basketball players in the country. I came to show the world who I was. I thought it was the Olympics, I was coming to show the world that I was one of the best players in the world.

Ian also wanted to use the WSAG and WYPS as an occasion to take part in high-level athletics:

I thought it would be more intense athletically, play soccer ... intense competition.
Gillian took advantage of the events as an outlet to be able to dance with similar elite performers, sharing that

I was a ballet dancer, and there are not many competitions around for ballet. So that triggered my desire.

Finally, Casey was a gifted tennis player who aimed to enhance her game. She hoped that competing versus similar opponents would advance her skills:

[One] goal was to really improve in my tennis, because I'm really competitive in my tennis. I really wanted to improve.

As noted in motivation research, competition and success can impact an individual's motivation towards sport participation. Ryan and Lockyer (2002) state that the presence of others of the same skill set could serve as a benchmark and create an emphasis on personal performance. At the WSAG and WYPS, participants had a wide variety of desires to take part in the events based on their talent level. While some wanted to attend to compete against the best and test their talents, others just wanted an opportunity to learn and improve their personal skill set. Considering many WSAG and WYPS participants were "elite" at their sport or fine arts activity, competition and winning most likely did not diminish intrinsic desires to take part in the event. This is supported by previous research suggesting that success and positive competitive experiences instead of defeat or negative emotions can result in intrinsic motivations (McAuley \& Tammen, 1989; Vallerand, Gauvin, \& Halliwell, 1986).

Opportunity for Travel and New Experiences. Finally, the WSAG and WYPS were able to provide the opportunity for participants to travel around the world or across the country. Researchers focusing on festival attendees have also noted the importance of having new experiences (Bowen \& Daniels, 2005; Crompton \& McKay, 1997) that travel could provide. This theme of travel and seeking new experiences was also common at the Australian University Games (Xu \& Pegg, 2007). Thus, travel and new experiences served as a motivation for some 
participants to attend the WSAG and WYPS. Having the chance to travel to the US provided an opportunity that normally might not have been available to many of the participants. Gillian was one example of an individual who yearned for a chance to visit America:

I think what motivated me was to actually come to a US college and be in a dorm and have that experience. In Mexico we don't have dorms or colleges, or we don't go away from home to study so that was a very American way of life, so having that experience as well.

Jackie also embraced the experience and was motivated because of the unique opportunity to travel:

It seemed like a really good opportunity and a once in a life time chance to come here.

Caryn believed that taking part in the WSAG and WYPS would provide benefits and a chance for self-improvement, relating that

I was very interested because I would go to the United States, and perhaps improve my English.

Others wished to experience the US culture and see the sites of the country, such as the Irish delegation that left campus one day to visit Boston and see more of New England. Thus, a basic motivational factor influencing participants' desire to attend the WSAG and WYPS revolved around the opportunity to travel and experience the US culture.

\section{General Discussion}

The purpose of this research was to ascertain the motivational factors that drew participants from around the world to the WSAG and WYPS. Whereas previous research has been conducted on participant motivation with regard to large-scale sport events (Vallerand, 1997, 2007; Funk et al., 2007; Ramchandani \& Coleman, 2012; Xu \& Pegg, 2007) and international cultural festivals (Bowen \& Daniels, 2005; Crompton \& McKay, 1997; Nicholson \& Pearce, 2001), this study makes a unique contribution in that it develops a conceptual framework illuminating the initial motivations of individuals to take part in a large-scale, elite, multinational SFD event centered upon fostering peace, understanding, and cultural acceptance. In this two-study investigation, we quantitatively and qualitatively explored participant motivations in an effort to guide theory development of motivations to take part in SFD events and address a gap in the literature examining SFD event motivations. This is an important undertaking, as SFD events often combine sports with cultural and educational activities and programming to achieve their missions, instead of solely focusing on athletic competition (Lyras \& Welty Peachey, 2011; Schulenkorf \& Edwards, 2012). As such, participant motivations to engage in these combined events could be different from either mainstream sport events or cultural events and festivals.

Our conceptual framework identifies World Learning, Skill Development, and Travel as the primary motivators. As seen in the findings of Study 1, the strongest motivator to take part in the WSAG and WYPS was World Learning. This finding was supported by respondents in Study 2, who repeatedly stated that the most influential motivational factors were the desire to meet new people, develop friendships, learn about other cultures, and give back to the community through altruistic actions, all aspects of World Learning. The World Learning factor includes elements from several motivational dimensions, including socialization (see also Bowen \& Daniels, 2005; Crompton \& McKay, 1997; Cunningham, 2007; Gill et al., 1983; Manfredo et al., 1996; Recours et al., 2004), learning about different cultures (Crompton \& McKay, 1997; Spaajj, 2009; Sugden, 2008), and the social justice-oriented motivation of becoming a better world citizen (Lyras \& Welty Peachey, 2011; Schulenkorf \& Edwards, 2012; Welty Peachey et al., 2013). World Learning was also a more prominent factor for international participants than participants from the US. Due to the nature and amount of conflict in the world taking place in some international participants' home countries, it could be that international youth were more attuned to the need for working at peace and conflict resolution strategies, and thus embraced the mission of the WSAG and WYPS to a greater extent than young people from the US, who could be more insulated from these agendas. For example, research has noted strong national identity or patriotism in Americans, 
some of whom have a tendency to display derogatory attitudes towards other nations (Li \& Brewer, 2004; Sidanius \& Petrocik, 2001).

Both studies contribute to our conceptual framework by revealing that the second and third most influential motivational factors were Skill Development and Travel, respectively, where participants were motivated to take part in elite competition, improve their athletic or artistic skills, or travel to or within the US to explore and experience a new environment. However, fine arts participants were motivated by the opportunity to improve their skills to a lesser extent than the sport participants. Some sport participants mentioned that they viewed the WSAG in particular as a sport camp, which traditionally a young athlete attends in order to work with high-quality coaches to improve one's skills and engage in competition and tournaments. Thus, some sport participants would be motivated by skill development. Fine arts participants, however, may not have viewed the WSAG as a camp for skill improvement, but rather as an educational program where new friends could be made and where they would be challenged intellectually to strive to make a difference in the world. During the WSAG, fine arts participants also worked together to create collaborate projects, such as a showcase closing ceremonies where all cultural groups performed together. These collaborative projects may have resulted in World Learning being a stronger motivator than Skill Development. However, these preliminary conclusions warrant future investigation.

Thus, the current research has helped shape a conceptual framework for understanding participant motivations for SFD events, drawn from various literature bases, including leisure, physical activity, sport, and festivals. Further, the peace and social justice component of the WSAG and WYPS, which aligned with the world citizenship facet of the World Learning factor, was instrumental in attracting participants who had motivations different from individuals who participated in other large-scale, multinational sporting events without a SFD emphasis. Instead of being primarily motivated by competition and rewards, as is the case at many international sporting events (Vallerand, 1997, 2007), the WSAG and WYPS participants, even those who were exceptional athletes and fine artists, were motivated more by the opportunity to make a difference in the world and in one's local community (world citizenship) and by the social aspects of the event (socialization). Anecdotally, our findings are similar to a report suggesting that young people are motivated to take part in the Model UN to learn more about other cultures, develop as world citizens, and make good friends (Muldoon, 1995). The Model UN is a non-sport initiative of the United Nations designed as an academic simulation that allows young people to learn about other countries and cultures and develop leadership skills. It is interesting that our findings differed slightly from Dickson's (2010) findings with the Australian Scholar-Athlete Games, where it was found that the most significant motivator was to develop new skills and ideas. One explanation could be that local organizers of the Australian Scholar-Athlete Games placed a greater emphasis on skill development in their marketing literature than on developing peace agendas and learning how to implement action plans for change at the community level. The marketing literature of the WSAG, and the WYPS in particular, had a concerted emphasis on the latter.

\section{Contributions, Implications, and Future Research}

While remaining mindful of potential limitations (e.g., data collected from a single event, socially desirable responses), this research does make several contributions. We have contributed to event motivation theory by drawing forth and refining (through both quantitative and qualitative efforts) a conceptual framework of participant motivations for taking part in SFD events that combine sport, cultural, and educational platforms. Theoretically, we have identified three motivational factors that could be unique in their relative importance and strength from motivations to attend other elite, multinational sporting events, from cultural, music, or arts festivals, or even from other SFD events that have different foci (e.g., sport event interventions working with disadvantaged youth, or initiated to help combat obesity). These factors of World Learning, Skill Development, and Travel can be incorporated into theories of motivation in the SFD event context and serve to guide future researchers in their efforts.

From a practical standpoint, these findings imply that SFD events with a peace and conflict resolution 
focus should highlight socialization opportunities and the mission of the organization, while still providing an environment of healthy competition and skill development. Green and Chalip (1998) suggest "the outcomes players seek need to be understood in more than merely sport-specific terms" (p. 285). In that same vein, it may be more important in marketing efforts to emphasize the opportunity to make new friends and learn about other cultures than to participate in elite competition. It is also important for organizers of these events to not shy away from their missions, and to market these events as opportunities to learn about and engage with world issues, meet people from other cultures, and develop strategies for change that can be taken back to the local communities. Organizers may also wish to target potential international participants with marketing strategies that focus more on the mission of the event and travel possibilities, while emphasizing the opportunity for skill development to a greater degree with potential US participants. SFD event organizers should provide ample opportunity for young people to socialize and interact with individuals from different cultures and countries, using mixed-nation teams and activity groups and creating ancillary social events (e.g., concerts, coffee houses, field trips, talent nights) to capitalize on World Learning as a motivator. Emphasis should also be given to designing competitive teams and hiring quality coaches and instructors to meet the need for skill development.

As this was one of the first preliminary investigations into participant motivations for a multinational SFD event, there are various agendas that can be pursued with future research. First, similar studies on participant motivation need to be conducted with other SFD events that have similar and dissimilar missions in order to refine the conceptual framework presented here. It may be that cultural context and location, as well as other situational and economic variables, could result in different motivational factors being salient for another SFD event centered on peace that is held at a different time and in a different area of the world, such as Africa, the Middle East, or China. It must be noted that the present investigation only examined initial participant motivations, and not how these motivations were then reflective of participant retention. This was outside the scope of the present study, as
WSAG and WYPS participants would only be able to attend one WSAG due to age restrictions. For other SFD events, however, participant retention would be of prime concern. Given the importance of SFD events for promoting peace and justice, all efforts aimed at improving them and encouraging participation are needed and welcome.

\section{References}

Bowen, H. E., \& Daniels, M. J. (2005). Does the music matter? Motivations for attending a music festival. Event Management, 9(3), 155-164.

Chelladurai, P. (1992). A classification of sport and physical activity services: Implications for sport management. Journal of Sport Management, 6, 38-51.

Creswell, J. W. (1998). Qualitative inquiry and research design: Choosing among five traditions. Thousand Oaks, CA: Sage.

Crompton, J. L., \& McKay, S. L. (1997). Motives of visitors attending festival events. Annals of Tourism Research, 24(2), 425-439.

Cunningham, G. B. (2007). Development of the Physical Activity Class Satisfaction Questionnaire (PACSQ). Measurement in Physical Education and Exercise Science, 11, 161-176.

Cunningham, G. B., \& Melton, E. N. (2012). Prejudice against LGB coaches: The influence of race, religious fundamentalism, modern sexism, and contact with sexual minorities. Sociology of Sport Journal, 29, 283-305.

Dickson, C. (2010). The Scholar-Athlete Games: Experiencing sport, culture and art. International Journal of Event Management Research, 5, 62-71.

Ercikan, K., \& Roth, W. M. (2006). What good is polarizing research into qualitative and quantitative? Educational Researcher, 35(5), 14-23.

Federation of Gay Games. (n.d.). Frequently asked questions. Retrieved from http://gaygames.org/wp/missionand-values/frequently-asked-questions/frequentlyasked-questions-about-the-gay-games-and-the-fgg

Ford, M. (1992). Motivating humans: Goals, emotions, and personal agency beliefs. Newbury Park, CA: Sage.

Funk, D. C., Toohey, K., \& Bruun, T. (2007). International sport event participation: Prior sport involvement; destination image; and travel motives. European Sport Management Quarterly, 7(3), 227-248.

Gill, G., Gross, J., \& Huddleston, S. (1983). Participation motives in youth sports. International Journal of Sport Psychology, 14, 1-14.

Green, B. C., \& Chalip, L. (1998). Sport tourism as the celebration of subculture. Annals of Tourism Research, 25(2), 275-291.

Hair, Jr., J. F., Black, W. C., Babin, B. J., Anderson, R. E., \& Tatham. R. L. (2006). Multivariate data analysis (6th ed.). Upper Saddle River, NJ: Pearson.

Krueger, R. A., \& Casey, M.A. (2009). Focus groups: A practical guide for applied research. London: Sage. 
Li, Q., \& Brewer, M. B. (2004). What does it mean to be an American? Patriotism, nationalism, and American identity after 9/11. Political Psychology, 25(5), 727-739.

Luthans, F. (1998). Organizational behavior (8th ed.). Boston: Irwin McGraw-Hill.

Lyras, A., \& Welty Peachey, J. (2011). Integrating sportfor-development theory and praxis. Sport Management Review, 14(4), 311-326.

Manfredo, M. J., Driver, B. L., \& Tarrant, M. A. (1996). Measuring leisure motivation: A meta-analysis of the recreation experience preference scales. Journal of Leisure Research, 28(3), 188-213.

McAuley, E., \& Tammen, V. V. (1989). The effects of subjective and objective competitive outcomes on intrinsic motivation. Journal of Sport \& Exercise Psychology, 11, 84-93.

Muldoon, J. P. (1995). The Model United Nations revisited. Simulation \& Gaming, 26(1), 27-35.

Nicholson, R., \& Pearce, D. (2001). Why do people attend events?: A comparative analysis of visitor motivations at four South Island events. Journal of Travel Research, 39, 449-460.

Ramchandani, G. M., \& Coleman, R. J. (2012). The inspirational effects of three major sport events. International Journal of Event and Festival Management, 3(3), 257-271.

Recours, R. A., Souville, M., \& Griffet, J. (2004). Expressed motives for informal and club/association-based sports participation. Journal of Leisure Research, 36(1), 1-22.

Riemer, H. A., \& Chelladurai, P. (1998). Development of the Athlete Satisfaction Questionnaire (ASQ). Journal of Sport \& Exercise Psychology, 20(2), 127-156.

Ryan, C., \& Lockyer, T. (2002). Masters’ Games-The nature of competitors' involvement and requirements. Event Management, 7(4), 259-270.

Schulenkorf, N., \& Edwards, D. (2012). Maximizing positive social impacts: Strategies for sustaining and leveraging the benefits of intercommunity sport events in divided societies. Journal of Sport Management, 26, 379-390.

Sherry, E. (2010). (Re)engaging marginalized groups through sport: The Homeless World Cup. International Review for the Sociology of Sport, 45, 59-71.

Sidanius, J., \& Petrocik, J. R. (2001). Communal and national identity in a multiethnic state: A comparison of three perspectives. In R. D. Ashmore, L. Jussim, \& D. Wilder (Eds.), Social identity, intergroup conflict, and conflict resolution (pp. 101-129). Oxford, UK: Oxford University Press.

Spaajj, R. (2009). Sport as a vehicle for social mobility and regulation of disadvantaged urban youth. International Review for the Sociology of Sport, 44, 247-264.

Strauss, A., \& Corbin, J. (1990) Basics of qualitative research: Grounded theory procedures and techniques. Newbury Park, CA: Sage.

Sugden, J. (2008). Anyone for football for peace? The challenges of using sport in the service of co-existence in Israel. Soccer \& Society, 9, 405-415.

Treasure, D. C., \& Roberts, G. C. (1994). Cognitive and affective concomitants of task and ego orientations during middle school years. Journal of Sport and Exercise Psychology, 16, 15-28.

Treasure, D. C., \& Roberts, G. C. (1998). Relationship between female adolescents' achievement goal orientations, perceptions of motivational climate, belief about success and sources of satisfaction in basketball. International Journal of Sport Psychology, 29, 211-230.

Vallerand, R. J. (1997). Toward a hierarchal model of intrinsic and extrinsic motivation. In M. P. Zanna (Ed.), Advances in experimental social psychology (Vol. 29, pp. 271-360). San Diego: Academic.

Vallerand, R. J. (2007). Intrinsic and extrinsic motivation in sport and physical activity: A review and a look at the future. In G. Tenenbaum \& R. Eklund (Eds.), Handbook of sport psychology (3rd ed, pp. 49-83). New York: John Wiley.

Vallerand, R. J., Gauvin, L. I., \& Halliwell, W. R. (1986). Negative effects of competition on children's intrinsic motivation. Journal of Social Psychology, 126(5), 649-657.

Welty Peachey, J., Cohen, A., Borland, J., \& Lyras, A. (2013). Building social capital: Examining the impact of Street Soccer USA on its volunteers. International Review for the Sociology of Sport, 48, 20-37.

$\mathrm{Xu}$, R., \& Pegg, S. (2007). Exploring the motivations for participant engagement in the Australian University Games. International Journal of Event Management Research, 3(2), 39-46. 